\title{
A Propriedade Intelectual em uma Relação Contratual Compreendendo Inteligência Artificial
}

\author{
Intellectual Property in a Contractual Relationship Involving Artificial \\ Intelligence
}

\author{
Nilza Maria Souza Altavini ${ }^{1}$ \\ Daniela da Silva Gumieiro ${ }^{1}$ \\ Flávia Oliveira Pereira ${ }^{1}$ \\ Rejane Sartori ${ }^{1,2}$ \\ ${ }^{1}$ Universidade Estadual de Maringá, Maringá, PR, Brasil \\ ${ }^{2}$ UniCesumar, Maringá, PR, Brasil
}

\begin{abstract}
Resumo
O avanço tecnológico exige que as empresas acompanhem as revoluções que se propagam. Com a inteligência artificial, os processos produtivos são maximizados por meio da automação, impondo, porém, atenção e aprimoramento da gestão da propriedade intelectual. Nesse contexto, o presente trabalho pretende analisar um contrato de licença de uso de um software que promove a inteligência artificial em uma planta industrial, firmado entre uma usina $e$ um fornecedor de software, para identificar sua adequação às garantias de proteção das criações envolvidas. Este estudo configura-se como exploratório e descritivo, com abordagem qualitativa. A coleta de dados foi realizada a partir de pesquisa documental e de campo, sendo esta efetuada em uma usina sucroenergética paranaense. Os resultados revelam que o processo de contratação carece de fundamentos da gestão da propriedade intelectual $e$ de bases legais e de segurança jurídica, conduzindo à necessidade de aperfeiçoamentos.
\end{abstract}

Palavras-chave: Inteligência Artificial. Propriedade Intelectual. Segredo Industrial.

\begin{abstract}
As technology advances companies are required to keep up with the revolutions that follow. Artificial intelligence allows productive processes to be maximized through automation but it imposes attention and enhancement of intellectual property management. In this context the present work aims to analyze a software license agreement, signed between a sugar-energy plant and a software supplier, that promotes artificial intelligence in an industrial plant to identify its suitability to the intellectual property aspects. This research is arranged as exploratory and descriptive with a qualitative approach. Data was acquired from documents and field research carried out in a sugar-energy plant in the State of Paraná. The results show that the hiring process lacks fundamentals about the management of intellectual property as well as a legal basis and certainty which requires the plant to pay more attention to the legal foundations inherent to intellectual property.
\end{abstract}

Keywords: Artificial Intelligence. Intellectual Property. Industrial Secret.

Área Tecnológica: Engenharias. Computação. Química. 


\section{Introdução}

Mundialmente, discute-se, no âmbito da academia, empresas e governos, acerca dos avanços da tecnologia sobre as demandas do presente e do futuro em relação aos produtos, processos e serviços. Tarefas manuais estão mais sujeitas a erros e, muitas vezes, demandam um tempo incompatível com a eficiência na linha produtiva, implicando em desperdícios. Respostas rápidas, com tomadas de ações assertivas e em tempo real, auxiliam em reduções de custos, aumento da produtividade, eficiência, eficácia e, consequentemente, em vantagem competitiva. Nesse cenário surgem as máquinas, que não se referem simplesmente aos equipamentos em si, mas ao novo modelo utilizado no contexto da indústria 4.0, otimizando os fluxos produtivos e promovendo a maximização da lucratividade de uma empresa.

A indústria 4.0 ou Quarta Revolução Industrial se caracteriza pela evolução dos sistemas incorporados aos sistemas ciber-físicos (GTI, 2014). Esse novo movimento trouxe soluções que potencializam a competitividade do mercado, como a internet das coisas, o big data analytics, cloud computing, a segurança cibernética, os robôs autônomos, a simulação, a manufatura aditiva, a realidade aumentada e a inteligência artificial (SOUZA et al., 2017). A inteligência artificial se utiliza da automação para não haver interferência humana nos processos, nos quais vários sistemas de gestão e controles se fazem presentes para operar máquinas e equipamentos, executar rotinas, entre outras atividades, para diminuição ou eliminação da realização manual (TOTVS, 2019).

As plantas industriais são reativas, ou seja, reagem apenas quando existem interferências em seus processos produtivos, mudanças econômicas, consumidores, tendências de manutenção e operação, e muitas vezes essas questões ocasionam prejuízos em produção, custo, segurança e qualidade. As novas tecnologias surgem como uma solução para ambientes mais dinâmicos, com pessoas, equipamentos e um grande número de informações. Cita-se como exemplo o setor sucroenergético, que, no início da década de 1980, evoluiu com a automação industrial, substituindo controles pneumáticos por eletrônicos; na década de 1990, utilizou-se de redes industriais e do início deste século XXI conta com centro de operações comandando toda a planta. As tecnologias utilizadas são controladores programáveis, todos conectados em redes de informações e controles (VENTURELLI, 2015).

O impacto dessas mudanças ocasionou um retorno financeiro positivo para uma usina localizada no Estado do Paraná na ordem de $\mathrm{R} \$$ 4.800.000,00 em uma safra de 5.000 horas efetivas. A implantação de controles com inteligência artificial surge para balanços mássicos e energéticos por meio de um software em formato turn-key, integrando as modelagens com o sistema da empresa (MARIANI, 2018). Já para uma usina localizada no Estado de Goiás, o software gera $\mathrm{R} \$ 13.500,00$ por dia em lucratividade (CRUZ, 2018). A Raízen, maior produtora de açúcar do mundo, com 26 usinas no Brasil, contratou uma empresa para desenvolver um algoritmo capaz de prever os movimentos dos preços das commodities (BATISTA, 2019). A Tereos, um grupo francês com grande participação no Brasil, deseja obter uma redução de custos em $\mathrm{R}$ \$200.000.000,00, e para tanto, entre suas estratégias está a digitalização, que se somará a outras mudanças, como a implantação de sensores para captação de informações, as quais, posteriormente, poderão ser analisadas para melhor desempenho industrial, bem como o uso da inteligência artificial, capaz de complementar as informações e auxiliar o chão de fábrica. 
Estas ações, além de reduzirem os custos e melhorarem a produtividade, também aperfeiçoam a qualidade dos produtos e processos (VALOR ECONÔMICO, 2019).

A Quarta Revolução Industrial indica que está se vivendo uma transição, sem estabelecer um limite de implantação no novo cenário mercadológico (VENTURELLI, 2015). Em meio às mudanças na forma de trabalho surgem dúvidas de como o direito à proteção aos produtos está acompanhando o avanço acelerado das tecnologias emergentes, e ainda se as empresas estão se preparando para estas novas demandas de proteção. Sendo assim, o presente trabalho tem por finalidade analisar um contrato de licença de uso de um software que promove a inteligência artificial na planta industrial, firmado entre uma usina do ramo sucroenergético e um fornecedor de software, com vistas a identificar sua adequação às garantias de proteção sobre as criações oriundas do intelecto humano.

\section{Metodologia}

Para alcançar o objetivo proposto, esta pesquisa classifica-se como exploratória e descritiva, com abordagem qualitativa. Quanto aos procedimentos técnicos, configura-se como documental e de campo, sendo esta realizada com o objetivo de obter informações e/ou conhecimentos para um problema ao qual se busca uma resposta, para obter a comprovação de uma hipótese ou ainda para descobrir novos fenômenos ou as relações entre eles. Já a pesquisa documental é efetuada a partir de materiais que ainda não receberam tratamento analítico (PRODANOV et al., 2013).

A coleta de dados foi realizada durante os meses de maio e junho de 2019 em uma usina do ramo sucroenergético, localizada no Estado do Paraná. Inicialmente, por meio de observação, foram descritos os processos relacionados à produção de seus principais produtos, etanol, açúcar e energia, bem como identificados os dados controlados pela inteligência artificial. Posteriormente, foi efetuada uma análise do contrato firmado entre a usina e um fornecedor do software que promove a inteligência artificial na planta industrial, com o objetivo de avaliar os aspectos atinentes à proteção da propriedade intelectual.

\section{Resultados e Discussões}

As revoluções industriais estão mudando o mundo há mais de 250 anos. Essas mudanças trazem impactos significativos não apenas no âmbito industrial, mas também na sociedade, nas tecnologias, nos sistemas políticos. Com a transição do trabalho braçal para a energia mecânica, a Primeira Revolução Industrial ocorreu na segunda metade do século XVIII, na Inglaterra, marcada pelas ferrovias e máquinas a vapor, cujos resultados do seu impacto perduram até os dias de hoje. No final do século XIX, a transição para a produção em massa, devido à eletricidade e linha de montagem, marca a Segunda Revolução. Na década de 1960, a Terceira Revolução Industrial trouxe o conceito de revolução tecnológica, pois tecnologias como semicondutores, computação e internet impulsionaram esse novo movimento (SCHWABE, 2016).

$\mathrm{O}$ atual momento em que a sociedade se encontra é conhecido como a Quarta Revolução Industrial. Tecnologias como internet móvel, sensores mais eficientes e de menor custo, aprendizagem automática e inteligência artificial, caracterizam esse novo ciclo, trazendo rupturas em 
relação à Terceira Revolução Industrial (SCHWABE, 2016). Arbix et al. (2017) destacam que os motores essenciais para esta última Revolução são informação, integração e automação, trazendo ao big data maior agilidade e produtividade, agregando valor e flexibilidade.

A automação é um pilar essencial para a indústria no futuro. Para Rosário (2009, p. 18), trata-se de "[...] um conjunto de técnicas as quais se constroem sistemas ativos capazes de atuar com uma eficiência pelo uso das informações recebidas do meio onde atuam". Assim, o sistema se comporta como se fosse um operador humano, pois ao receber as informações, traz a melhor opção de ação corretiva, executando a mais apropriada. Ao relacionar automação com inteligência artificial, Ovanessoff e Plastino (2017) citam o crescimento que ambas as tecnologias trazem quando comparadas com as soluções tradicionais da automação. Esses autores destacam três recursos que foram impactados como novo fator de produção: tarefas físicas que requerem adaptabilidade, agilidade e aprendizagem são automatizadas; problemas são resolvidos em diferentes setores e funções; e autoaprendizagem devido à repetitividade em escala.

Por muito tempo a inteligência artificial foi vista como um investimento desnecessário, apesar de ser considerada uma tecnologia moderna e inovadora. Na atualidade é um elemento estratégico para os negócios, pois permite que as empresas aproveitem seus dados de forma satisfatória e, assim, melhorem sua eficiência e produtividade com resultados tangíveis (SALAZAR, 2018). Apesar da sua evolução e relevância, a construção de um futuro com a inteligência artificial ainda gera discussões, mas como afirmam Ovanessoff e Plastino (2017), o futuro dependerá de como a inteligência artificial será conduzida nesta transição.

As questões intelectuais, tecnológicas, políticas, éticas e sociais necessariamente precisam estar alinhadas às mudanças promovidas pela inteligência artificial. Nesse sentido, alguns tópicos ganham destaque, como preparar profissionais para trabalhar com essa nova tecnologia e adaptar os atuais trabalhadores com novos aprendizados e competências; fortalecer os ecossistemas de inteligência artificial, envolvendo a comunidade que está ativa na inovação; defender um código de ética para a inteligência artificial e adotar uma regulamentação facilitada.

O desenvolvimento tecnológico depende de um ambiente de propriedade intelectual, pois é por meio deste que os avanços das diversas esferas do conhecimento científico têm sido introduzidos nas bases produtivas das empresas e transformado seus padrões de organização (REIS; GOMES, 2017). Neste contexto, novas regulamentações serão necessárias e todas as partes precisam estar estruturadas, pois atrasos em sua implementação podem trazer grandes prejuízos (OVANESSOFF; PLASTINO, 2017).

\subsection{A Propriedade Intelectual e sua Relação com Software e Segredo Industrial}

Propriedade intelectual é conceituada por Di Blasi (2005) como o direito de pessoa física ou jurídica sobre um bem incorpóreo móvel. Araújo et al. (2010) afirmam tratar-se de um instrumento fundamental no cenário globalizado competitivo, no qual o conhecimento e a capacidade de inovar têm papel importante, consistindo em um diferencial de competitividade. 
No Brasil, a propriedade intelectual foi incluída dentre os direitos e garantias fundamentais, descritos no artigo $5^{\circ}$ da Constituição Federal, especialmente nos incisos XXVII a XXIX ${ }^{1}$. Está dividida em Direito Autoral, que compreende direitos de autor, direitos conexos e programas de computador; Proteção Sui generis, que inclui topografia de circuito integrado, conhecimentos tradicionais e cultivares; e Propriedade Industrial, que envolve marca, desenho industrial, segredo industrial, indicação geográfica e patente (ARAÚJO et al., 2010).

Em 1998 foi promulgada a Lei de Software (Lei n. 9.609/98), paralelamente com a nova Lei de Direitos Autorais (Lei n. 9.610/98), que regula, além dos programas de computador, outros bens imateriais. Ambas as leis promovem a adequação do Brasil às normas internacionais, enquadrando a proteção para programas de computador (software) por meio do direito autoral, formato vigente até então.

Wachowicz (2014, p. 4) explica que "[...] o registro da obra tutelada pelo direito autoral é facultativo e meramente declaratório, dependendo da natureza da obra esta será registrada em órgão específico, podendo, no entanto, comportar mais de um registro dependendo da afinidade que possuir". Assim, muito embora seja facultativo o registro, basta apenas a publicação ou divulgação para que determinada obra tenha proteção, e dependendo da natureza será registrada em órgão específico. No Brasil, o órgão responsável pela proteção de software é o Instituto Nacional da Propriedade Industrial (INPI) e tem abrangência internacional. Da mesma forma, programas estrangeiros procedentes de países que concedam reciprocidade aos autores brasileiros também não precisam ser registrados no Brasil, e ainda conforme a lei vigente, o prazo de validade dos direitos autorais é de 50 anos contados a partir de $1^{\circ}$ de janeiro do ano subsequente ao da sua publicação ou, na ausência desta, da sua criação (ANDRADE et al., 2007). Como explicam Tigre e Marques (2009), na tradição do direito autoral, a proteção não recai sobre a ideia ou utilidade de um software, mas sim sobre a sua forma de expressão. Veiga (1998) complementa afirmando que o que não pode ser copiado é seu código-fonte.

Pereira (1999) explica que o software pode ser caracterizado como um conjunto de comandos e instruções capazes de fazer uma máquina de tratamento de informação realizar certas funções e tarefas e que tem com a máquina uma dependência funcional. Em outras palavras, afirma que "[...] o computador é, pois, uma máquina de tratamento de informação que executa software, isto é, que utiliza software para desempenhar as funções e executar as tarefas que lhe permite o software utilizado" (PEREIRA, 1999, p. 3).

Por ser o software um bem econômico muito valioso é que se faz necessária a sua proteção jurídica, sendo que o acordo pelo qual o titular dos direitos concede a outrem uma autorização de uso do programa de computador, ou de cópia deste, para determinados fins é denominado contrato de licença (PEREIRA, 1999). Nesse tipo de contrato, as obrigações do licenciante são advindas da transferência do uso de determinado software, sendo assim, o que se transfere interpartes nessa espécie contratual não é o direito relativo à propriedade intelectual e industrial e sim o direito de uso, ou seja, não se transfere, portanto, os direitos autorais do software. Entre outras obrigações advindas desses contratos, inclui-se a proibição do licenciado que, possuindo

\footnotetext{
1"Art. $5^{\circ}$ Todos são iguais perante a lei, sem distinção de qualquer natureza, garantindo-se aos brasileiros e aos estrangeiros residentes no País a inviolabilidade do direito à vida, à liberdade, à igualdade, à segurança e à propriedade, nos termos seguintes: [...] XXVII - aos autores pertence o direito exclusivo de utilização, publicação ou reprodução de suas obras, transmissível aos herdeiros pelo tempo que a lei fixar; XXVIII - são assegurados, nos termos da lei: a) a proteção às participações individuais em obras coletivas e à reprodução da imagem e voz humanas, inclusive nas atividades desportivas; b) o direito de fiscalização do aproveitamento econômico das obras que criarem ou de que participarem aos criadores, aos intérpretes e às respectivas representações sindicais e associativas; XXIX a lei assegurará aos autores de inventos industriais privilégio temporário para sua utilização, bem como proteção às criações industriais, à propriedade das marcas, aos nomes de empresas e a outros signos distintivos, tendo em vista o interesse social e o desenvolvimento tecnológico e econômico do País; [...]".
} 
o direito ao uso do software, aproveite de seu código fonte para alterar aspectos funcionais para, posteriormente, fazer desse programa objeto de contrato de compra e venda. Da mesma forma deve o licenciado resguardar, inclusive, as informações técnicas de constituição funcional que são emanadas do software, pois assim preservará os direitos autorais do licenciante. Quanto à forma de uso do software, deverão ser estabelecidas cláusulas expressas no intuito de delimitar a utilização pelo usuário final, cabendo ao licenciado usar o software de acordo com o indicado pelo licenciante, proprietário do aplicativo e do código fonte (IZIDORO, 2012).

Ainda no domínio da relação de direitos e deveres relativos à propriedade intelectual, importa citar o Segredo Industrial, que nos dizeres de Loiola e Mascarenhas (2013, p. 5) é o "[...] meio de proteção do bem intelectual assegurado por cláusulas específicas, inseridas em contratos de know-how, acordos de confidencialidade e similares". Rossi (2016) inclui o segredo industrial dentre os regimes jurídicos de proteção de informação no marco dos direitos de propriedade intelectual e explica que a proteção jurídica que dele advém recai sobre a divulgação não autorizada, que pode culminar com a responsabilização de quem assim proceda, mas não há apropriação do conteúdo do segredo por seu detentor. Conclui que "[...] confidencialidade, então, é o regime jurídico que protege o acesso a dado, informação ou conhecimento com caráter secreto, sigiloso ou reservado" (ROSSI, 2016, p. 149).

No mesmo sentido, ao tratar do segredo industrial na legislação de propriedade intelectual em vigor no Brasil e ressaltando que esta proteção pressupõe um ambiente de concorrência, Barbosa (2010) explica que são considerados crimes os atos de divulgar, explorar ou utilizar, sem autorização, conhecimentos, informações ou dados confidenciais aplicáveis na indústria, comércio ou prestação de serviços, excluídos os de conhecimento público ou evidentes para um técnico no assunto, cujo acesso tenha decorrido de relação contratual ou empregatícia, mesmo após a rescisão contratual, ou que tenham sido obtidos por meios ilícitos ou mediante fraude.

As ideias não patenteáveis encontram-se inseridas em uma das áreas mais frágeis das criações intelectuais, já que não são protegidas pelo regime de direitos autorais, tampouco pelo sistema de proteção aos segredos de negócios, razão porque se deve estar alerta para o fato de que os compromissos contratuais de confidencialidade representam um mecanismo essencial para a salvaguarda dos interesses do disseminador de uma determinada ideia (BENEVIDES, 2015).

\subsection{A Usina Sucroenergética e seus Processos}

Em uma usina sucroenergética é a cana-de-açúcar a matéria-prima responsável pelo processo produtivo, sendo que os principais produtos são etanol, açúcar e energia. O objetivo de uma empresa desse ramo é realizar o processamento da cana, extraindo o máximo de sacarose, que é o produto destinado à produção do açúcar. Quando há a quebra desta molécula em glicose e frutose volta-se sua produção para o etanol.

As etapas de processamento da unidade produtora objeto de estudo, cujo mix de produtos compreende $80 \%$ de açúcar e $20 \%$ de etanol, são a seguir descritas:

a) Recepção, preparo e moagem: a cana é descarregada em mesas alimentadoras, em forma mecanizada e manual. Em seguida, passa por equipamentos picadores e desfibradores. Nos rolos compressores é moída e o bagaço é enviado para as caldeiras, sendo este utilizado como combustível para a geração de energia térmica, mecânica e elétrica da planta. 
b) Tratamento do caldo: o caldo extraído passa por tratamento físico (peneiramento), químico (dosagem de cal, polímero e enxofre) e térmico (aquecedores).

c) Evaporação: após o tratamento o caldo é enviado para equipamentos denominados evaporadores e caixas de evaporação, havendo concentração do caldo, denominado nesta etapa de xarope.

d) Cristalização e cozimento: para completar a evaporação o xarope passa por equipamento sob vácuos e se realiza a granulação, formando os cristais com o mel mãe.

e) Centrifugação: a separação dos cristais de sacarose do mel mãe é realizada pela centrifugação. $\mathrm{O}$ açúcar é destinado ao secador. Nesta etapa há, também, a separação dos méis - rico $\mathrm{A}$, rico $\mathrm{B}$, pobre $\mathrm{A}$, pobre $\mathrm{B}$ e mel final.

f) Secador: o açúcar entra em contato com o ar quente, submetido a uma temperatura de $38^{\circ} \mathrm{C}$, para a retirada de umidade, garantindo uma melhor conservação do produto.

g) Armazenagem: o açúcar, por meio de correias transportadoras, é enviado para o armazém para aguardar sua expedição.

h)Fermentação: o mel final extraído da centrifugação é destinado para o processo fermentativo. Antes, há a preparação do mosto, quando esse mel é misturado à água e caldo clarificado. Neste processo os açúcares contidos no mosto são convertidos em etanol e gás carbônico por meio de reações químicas provocadas por micro-organismos, denominados leveduras.

i) Centrifugação: o vinho bruto (levedura + mosto) passa por centrifugação para a separação do vinho e da levedura. O micro-organismo é reutilizado nos processos seguintes e o vinho centrifugado é destinado para destilação.

j) Destilação: por diferentes pontos de ebulição, os aparelhos de destilação separam o etanol em concentração de 92,6 a 93,3 \% (m/m). O subproduto desse processo é a vinhaça, destinada para fertirrigação nas lavouras. Cita-se também o óleo fúsel, utilizado em indústrias químicas e de cosméticos.

k) Tanques de armazenamento: o etanol produzido é armazenado em tanques expedidores.

O bagaço extraído da moenda é responsável pela geração de toda energia da planta industrial, incluindo sua exportação para a venda. O processo se dá da seguinte forma:

a) Duas caldeiras, com capacidade de produção de 160 toneladas de vapor por hora, produzem o vapor vivo $\left(21 \mathrm{kgf} / \mathrm{cm}^{2}\right)$ para as turbinas existentes no preparo e rolos da moenda. Podem também alimentar as turbobombas de alimentação de água das caldeiras.

b) O vapor que sai das turbinas do preparo e da moenda passa a ser denominado vapor de escape $\left(1,5 \mathrm{kgf} / \mathrm{cm}^{2}\right)$ e é absorvido pelo processo.

c) Uma parte do vapor vivo destina-se ao gerador de condensação e a água condensada é enviada para o desaerador, que alimenta os equipamentos. O excedente libera energia para venda.

d) Uma terceira caldeira de 160 toneladas de vapor por hora $\left(65 \mathrm{kgf} / \mathrm{cm}^{2}\right)$ vai para uma turbina de contrapressão, sendo que parte da energia gerada supre as necessidades do processo e a maior parte é vendida. O equipamento também é de extração. 
e) No decorrer das linhas de vapores há válvulas rebaixadoras de $65 \mathrm{kgf} / \mathrm{cm}^{2}$ para $21 \mathrm{kgf} /$ $\mathrm{cm}^{2}$ e $1,5 \mathrm{kgf} / \mathrm{cm}^{2}$ e de $21 \mathrm{kgf} / \mathrm{cm}^{2}$ para $1,5 \mathrm{kgf} / \mathrm{cm}^{2}$, buscando equilíbrio no processo caso ocorra algum problema em determinada etapa.

Conforme exposto, a planta industrial envolve muitos processos e variáveis que devem ser controlados para minimizar perdas, extraindo o máximo de resultados. Os controles operacionais eram automatizados, mas ficavam sob a responsabilidade dos operadores alterarem os cenários para operacionalizar a planta, denominados de set point de controles. Quando se fala em variáveis controláveis pela indústria se pode citar como principais as pressões, temperaturas, açúcares, não açúcares, fibra da cana, quantidade de água necessária para a planta e insumos utilizados. Fibra, açúcares e não açúcares são itens predominantemente agrícolas, assim como a entrada de impurezas minerais e vegetais.

As impurezas devem ser removidas do processo por meio de equipamentos e insumos $e$ dessa forma, embora exerçam grande interferência, são excluídas do círculo para priorizar a otimização do processo. Na maior parte do tempo de operação há controles sobre a quantidade e qualidade de extração dos açúcares, pois esses são responsáveis pelo açúcar e etanol produzidos, enquanto a fibra está ligada à produção do bagaço (combustível para geração de energia da planta e exportação de energia). Essas entradas resultam em muitas outras de controle operacional, sendo que na usina há 53.069 variáveis no banco de dados no sistema supervisório, sendo 79 manipuladas pelo software de otimização. Em relação à qualidade, o laboratório é responsável por emitir mais de 452 parâmetros que alimentam diversos boletins de controle. Todas as transformações das entradas para fabricar os produtos finais giram em torno de pressões, temperaturas e vazões. Os dois primeiros acarretam em balanços energéticos e o último em balanços mássicos para a usina. O processo é demonstrado na Figura 1.

Figura 1 - Variáveis macros de controle operacional

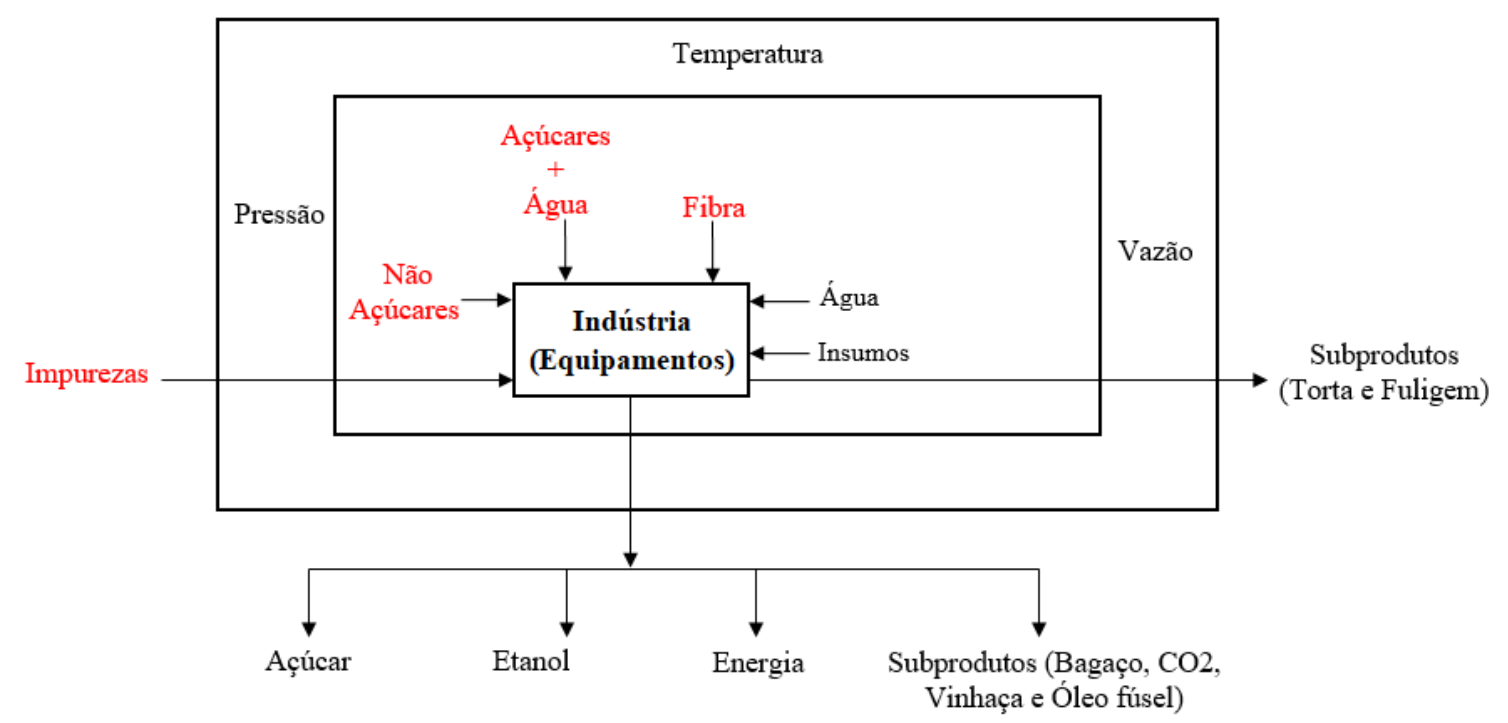

Fonte: Elaborada pelas autoras deste artigo

Todos esses pontos de controles relacionados à pressão, temperatura e vazões eram automatizados, e com o avanço das tecnologias e a necessidade do setor em melhor extrair resultados e desvencilhar-se das dependências humanas para otimizar a planta industrial, adotou-se um 
sistema inteligente que lê determinadas variáveis e as manipula para um melhor resultado em níveis de balanços mássicos e energéticos, com cálculos e atuações em tempo real. Dessa forma, os set points que recebiam intervenção humana passaram a ser aprendidos pela máquina e houve mudanças na operação de acordo com a necessidade da planta. Os dados de processo são lidos por um software, assim como os resultados analíticos que determinam a qualidade das operações pelo laboratório industrial.

Apesar de a planta industrial ainda não estar totalmente dotada de inteligência artificial, sua relevância se destaca a partir das variáveis aprendidas para controle, onde são observadas melhorias significativas nos balanços mássicos em relação a vazão de vapor para os processos por meio das válvulas redutoras e consumo de equipamentos; vazão de água adicionada para embebição da moenda; e vazão de caldo para evaporação, de caldo/mel/água para fermentação e de vinho para a destilação. Já para o balanço energético menciona-se pressão e temperatura de geradores de vapor, energia e equipamentos; equilíbrio termodinâmico nos aparelhos de destilação; e controle de potencial hidrogeniônico $(\mathrm{pH})$ para minimizar inversão da sacarose.

Para o ajuste, adaptação ou adequação dos mecanismos de inteligência artificial do software licenciado às especificidades e padrões do setor industrial da contratante, houve a contribuição de seus colaboradores com conhecimentos técnicos, desenvolvimento de modelos matemáticos, melhorias em processos, dados técnicos e priorização de temas para garantir uma melhor operacionalidade dos equipamentos, bem como condições ideais de variáveis de controles. Não se pode deixar de mencionar que os proprietários do software de otimização contribuíram de forma significativa para os trabalhos, com debates e discussões positivas, mas na maior parte os conhecimentos eram da contratante, isto é, da usina.

Os resultados de ganhos com a implantação de controles por inteligência artificial são expressivos, uma vez que a eficiência industrial aumentou, proporcionando um incremento em sua rentabilidade na ordem de $37 \%$ no ano de startup de todas as funcionalidades, isso em 2017. Os valores em reais não são divulgados a pedido de confidencialidade da empresa em estudo.

Na prática da relação contratual da empresa (contratante) com a licenciante do software (contratada), a identificação de melhorias nos processos se dá pela usina, que também formula a ideia e a repassa para a contratada, que então executa as adequações no software com seu código fonte e disponibiliza a melhoria para utilização na unidade produtora, conforme mostrado na Figura 2.

Figura 2 - Fluxo da Utilização do Software Responsável pela Inteligência Artificial

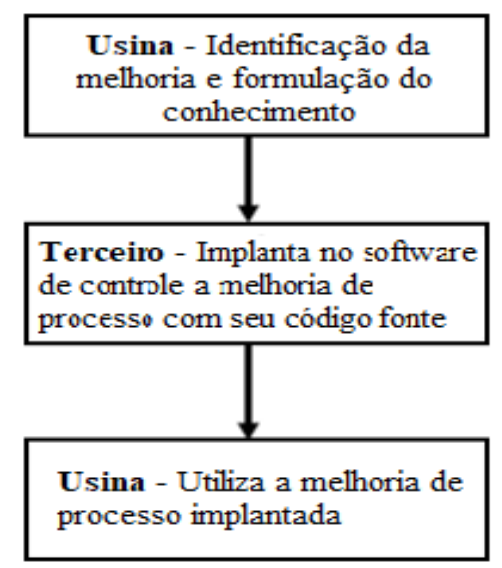

Fonte: Elaborada pelas autoras deste artigo 
Observa-se que o direito autoral do programa de computador é, efetivamente, da empresa terceirizada, enquanto as informações e dados oriundos dos colaboradores da usina para os ajustes nas funcionalidades do software se caracterizam por segredo industrial. Em vista desse processo e pelo fato de que essa relação decorre do contrato de licença de uso do software, indaga-se: o capital intelectual da empresa contratante está protegido, sob o enfoque da concorrência desleal, em prol de uma melhor vantagem competitiva no mercado? A contratação realizada pela usina em estudo foi baseada, de forma estratégica e segura, nos fundamentos que envolvem inteligência artificial, propriedade intelectual e segredo industrial? Esses questionamentos são analisados no contrato de licença de uso do software, o qual não será divulgado devido ao sigilo empresarial.

\subsection{Análise do Instrumento Contratual}

Em vista dos conceitos de indústria 4.0, a usina em estudo se caracteriza como uma planta inteligente, uma vez que grande parte de seus sistemas são operados por um software que busca dados operacionais e analíticos, e a partir da análise destes, atua no processo, conforme as necessidades, em tempo real. Entretanto, no que diz respeito aos aspectos práticos decorrentes da relação firmada, consideradas as atividades de implantação da inteligência artificial e os mecanismos de proteção da propriedade intelectual envolvidas, observa-se uma carência de aprimoramento jurídico em favor de ambas as partes contratantes.

Embora a intenção não seja transcrever cada uma das 17 cláusulas do contrato, inclusive pela limitação decorrente do sigilo, apresenta-se um breve resumo para demonstrar suas características. A cláusula referente ao objeto do contrato o descreve tão somente como "serviços de implantação de software" e indica o local de prestação do serviço. Essa informação é retomada em outro parágrafo, em "Objeto Detalhado", mas apenas fazendo referência a itens da proposta comercial relativas à modalidade aluguel e aos motivos quanto à opção por esta modalidade de contratação. Outra seção trata de condições comerciais, valor e sua composição, e em meio a essas condições mais uma vez há disposição quanto ao prazo de "validade" do contrato, forma de pagamento e reajustes, atrasos e multas moratórias.

As seções seguintes tratam das responsabilidades da contratada e da contratante. Para a primeira, há um rol maior de obrigações, mas sem qualquer especificidade relativa à natureza do contrato, qual seja, de licença de uso de um objeto de propriedade intelectual. Já para a contratante a única obrigação disposta na respectiva cláusula se refere à designação de um responsável para fornecer as informações necessárias para a execução do contrato. Já as seções finais dizem respeito apenas à garantia do serviço e aos motivos para a rescisão contratual, bem como trata das condições gerais.

De modo geral, o instrumento contratual é omisso quanto a informações mais completas em relação ao próprio software, ao licenciamento, aos direitos e obrigações das partes em face do objeto e do licenciamento e, acima de tudo, em relação ao sigilo/segredo quanto às informações obtidas pela contratada junto à usina para a implementação/melhoria do sistema. Apenas na última sessão do contrato é que se faz menção genérica a sigilo "sobre questões técnicas, contábeis, industriais, agrícolas e comerciais", pertinentes ao objeto do contrato, mas não há qualquer disposição que impeça, por exemplo, que encerrada a vigência do contrato possa a contratante dispor, conforme sua conveniência, das informações obtidas, o que poderá, inclusive, 
causar-lhe prejuízos em vista da possibilidade de utilização das informações pela concorrência e consequente perda da vantagem competitiva. Da mesma forma, não há qualquer acordo quanto à delimitação de pessoas, por parte da contratada, para o acesso a tais informações.

Todo o processo de implantação de uma inteligência artificial obteve, além de retornos financeiros significativos para a empresa, outras vantagens de fundamental relevância, tais como aprendizado, geração de conhecimento, lições aprendidas e crescimento da equipe, visto as mudanças de paradigmas com a interação entre máquinas e pessoas, além de capacitação tecnológica para os funcionários. Para a alta direção resultou em reflexão sobre a iniciativa de proteções por segredo industrial, prática que favorece a concorrência e competitividade no mercado, pois um contrato que não delimita todas as questões relacionadas à proteção legal dos ativos intangíveis da empresa pode favorecer outras de seguimento similar a utilizar os mesmos mecanismos de melhorias para obtenção de melhores resultados.

Algumas polêmicas envolvem os direitos de propriedade intelectual atinentes a programas de computadores, sendo que a legislação brasileira atual não atende, de forma completa, a todos os envolvidos. Há muitas lacunas na lei e é frágil o conhecimento para aqueles que produzem esses programas, maior carência há ainda em relação aos seus consumidores. Assim, o primeiro desafio é buscar orientações quanto à melhor forma, dentro dos limites legais, de estabelecimento das condições contratuais a partir das demandas da empresa, de suas necessidades $e$ expectativas, de capital humano e intelectual que detém, dentre outros fatores.

Há que se verificar, ainda, as diversas possibilidades de softwares disponíveis no mercado para o atendimento das necessidades de uma empresa do porte da usina objeto de estudo, tais como quais os produtos existentes no mercado e se atendem a contento as necessidades ou se as resolverá apenas paliativamente, demandando adequações; no caso destas serem essenciais, quem detém as informações e o conhecimento requerido; os custos envolvidos nesta contratação, se são vantajosos ou não em relação ao desenvolvimento de um produto próprio por um colaborador ou prestador de serviço especializado; e no caso de contratação, se na forma de licença de uso ou de aquisição.

\section{Considerações Finais}

A integração mundial por meio da globalização, que aproxima sociedades e nações, eliminando distâncias nas comunicações, lazer, comércio, entre tantos outros espaços do cotidiano de cada ser humano, se caracteriza, no ambiente produtivo, pelo estabelecimento de uma concorrência que não se detém para analisar a capacidade de competição de cada empresa. Independentemente dos fatores que promovem a globalização, que não são objeto deste estudo, fato é que nesse contexto não se admite inércia; a capacidade de inovar corresponde, praticamente, à capacidade de sobreviver, já que se trata de uma medida do diferencial de competitividade.

A inovação, por sua vez, pressupõe conhecimentos e tecnologias, frutos do intelecto humano, que justamente pelas características e efeitos da globalização precisam ser protegidos pela propriedade intelectual e/ou por acordos de sigilo. Possível concluir, portanto, que o conhecimento no âmbito das empresas, assim como a propriedade intelectual, deve ser considerado como fator estratégico, objeto de gestão. 
É praticamente impensável, na atualidade, que a operação de uma empresa ocorra sem a utilização de programas de computador, nas suas diversas frentes, para a otimização e agilização de suas atividades, impondo-se, na maioria das vezes, a contratação de licenças de uso de softwares. Em um ambiente empresarial, esses contratos devem merecer maior atenção dos gestores, com uma abrangência estratégica e não meramente operacional.

Várias informações poderão ser relevantes para a contratação de licenças pela empresa, como um contrato escrito "sob medida", de acordo com a situação da corporação, seja em razão do impacto nos custos; seja para evitar problemas jurídicos posteriores, que por sua vez também poderão implicar em custos e outros transtornos; seja pela possibilidade de atribuir valor ao conhecimento localizado dentro da empresa, com a possibilidade de, a partir deste, agregar valor ao produto de terceiros.

Por meio do estudo efetuado em uma usina sucroenergética, foi possível observar, a partir dos termos do contrato firmado, que de modo geral não há conhecimento especializado suficiente quanto às práticas gerenciais de propriedade intelectual e de capital intelectual que detém. Também pelo formato e conteúdo do contrato, não se observa articulação das ações que envolvem a propriedade intelectual contratada com as demais ações da empresa.

Nesse sentido, decorre naturalmente deste contexto a necessidade de elaboração, pela empresa estudada, de uma revisão, efetuada por profissional especializado, das condições que de fato envolvem a execução do contrato de licenciamento de software vigente para verificar a adequação destas às cláusulas pactuadas no contrato, no ensejo de evitar problemas no futuro $e$, inclusive, de avaliar a proteção de ativos em relação ao sigilo demandado ou até quanto ao interesse econômico da própria contratada.

\section{Referências}

ANDRADE, E. et al. Propriedade intelectual em software: o que podemos apreender da experiência internacional? Revista Brasileira de Inovação, [S.l.], v. 6, n. 1, p. 31-53, 2007.

ARAÚJO, E. F. et al. Propriedade Intelectual: proteção e gestão estratégica do conhecimento. Revista Brasileira de Zootecnia, [S.l.], v. 39, (supl. especial), p. 1-10, 2010. Disponível em: http://www. scielo.br/pdf/rbz/v39sspe/01.pdf. Acesso em: 19 jun. 2019.

ARBIX, G. et al. O Brasil e a Nova Onda de Manufatura Avançada: O que aprender com Alemanha, China e Estados Unidos. Novos Estudos: CEBRAP, São Paulo, v. 36, n. 3, p. 29-49, 2017. Disponível em: http://www.scielo.br/pdf/nec/v36n3/1980-5403-nec-36-03-29.pdf. Acesso em: $1^{\circ}$ jul. 2019.

BARBOSA, D. B. Uma Introdução à Propriedade Intelectual. São Paulo: Lumen Juris, 2010.

BATISTA, F. Raízen se volta ao algoritmo para prever preços de açúcar. Nova Cana, 11 de fevereiro de 2019. Disponível em: https:/www.novacana.com/n/acucar/mercado/raizen-algoritmo-preverprecos-acucar-110219. Acesso em: 22 jun. 2019.

BENEVIDES, L. de A. Os direitos de propriedade intelectual em face da engenharia. Revista Direito Mackenzie, [S.l.], v. 8, n. 1, p. 51-68, 2015. Disponível em: http://editorarevistas. mackenzie.br/index.php/rmd/article/viewFile/8121/5338. Acesso em: 26 jun. 2019. 
CRUZ, D. M. C.Software de inteligência artificial faz unidade da Goiás a ter ganho diário de $\mathrm{R} \$ 13,5$ mil. Jornal Cana, 19 set, 2018. Disponível em: https://jornalcana.com.br/software-de-inteligenciaartificial-faz-unidade-da-goiasa-ter-ganho-diario-de-r-135-mil/. Acesso em: 22 jun. 2019.

DI BLASI, G. A propriedade industrial: os sistemas de marcas, patentes e desenhos industriais analisados a partir da Lei n. 9.279, de 14 de maio de 1996. Rio de Janeiro: Forense, 2005.

GTI - GERMANY TRADE AND INVESTMENT. Industry 4.0: Smart manufacturing for the future. Berlin, 2014.

IZIDORO, W. Contrato de licença de uso de software transferência de tecnologia. 2012. Disponível em: http://egov.ufsc.br/portal/conteudo/contrato-de-licen\%C3\%A7a-de-uso-de-softwaretransfer\%C3\%AAncia-de-tecnlogia. Acesso em: 29 jun. 2019.

LOIOLA, E.; MASCARENHAS, T. Gestão de Ativos de Propriedade Intelectual: um Estudo sobre as Práticas da Braskem S.A. RAC, Rio de Janeiro, v. 17, n. 1, p. 42-63, jan./fev., 2013. Disponível em: http://www.scielo.br/scielo.php?pid=S1415-65552013000100004\&script $=$ sci_abstract\&tlng=pt. Acesso: 20 jul. 2019.

MARIANI, D. Paranacity comprova que é sempre possível evoluir e reduzir custos operacionais. Jornal Cana, [S.l.], série 2, n. 288, janeiro de 2018.

OVANESSOFF, A.; PLASTINO, E. Como a inteligência artificial pode acelerar o crescimento da América do Sul. 2017. Disponível em: https://www.accenture.com/_acnmedia/PDF-49/ Accenture-AI-America-do-Sul.pdfla=pt-BR\#zoom=50. Acesso: 26 jun. 2019.

PEREIRA, A. L. D. Programas de computador, sistemas informáticos e comunicações eletrônicas: alguns aspectos jurídico-contratuais. Revista da Ordem dos Advogados, [S.l.], n. 59, III, dez. 1999, Lisboa, p. 915-1.000. Disponível em: https:/eg.uc.pt/bitstream/10316/28734/1/PROGRAMAS\%20 DE\%20COMPUTADOR\%2c\%20SISTEMAS\%20INFORM\%c3\%81TICOS\%2c\%20ASPECTOS\%20 CONTRATUAIS.pdf. Acesso em: 29 jun. 2019.

PRODANOV, C. C. et al. Metodologia do trabalho científico: métodos e técnicas de pesquisa e do trabalho. 2. ed. Novo Hamburgo. Editora Feevale, 2013.

REIS, D. A.; GOMES, I. M. de A. Capital Humano, Intensidade da Inovação na Indústria e Crescimento Econômico no Brasil. Cadernos de Prospecção, Salvador, v. 10, n. 4, p. 721-737, out./dez. 2017. Disponível em: https://portalseer.ufba.br/index.php/nit/article/view/23474/23474. Acesso em: 16 dez. 2019.

ROSÁRIO, J. Automação Industrial. São Paulo: Editora Baraúna, 2009.

ROSSI, J. S. Confidencialidade em contratos de transferência de tecnologia de defesa. Revista Justiça do Direito, [S.l.], v. 30, n. 1, p. 143-167, jan.-abr., 2016. Disponível em: http://dx.doi. org/10.5335/rjd.v30i1.5766. Acesso em: 23 jun. 2019.

SALAZAR, O. Tecnologia do futuro? Inteligência Artificial gera vantagem competitiva hoje.

Empresas e negócios, 16 março de 2018. Disponível em: https:/jornalempresasenegocios.com.br/ PDFc/3587/pagina_07_ed_3587.pdf. Acesso em: 22 jun. 2019.

SCHWABE, K. A Quarta Revolução Industrial. São Paulo: Edipro, 2016.

SOUZA, E. et al. Indústria 4.0: contribuições para setor produtivo moderno. In: ENCONTRO NACIONAL DE ENGENHARIA DE PRODUCAO, Joinvile. 4. Anais [...], Joinvile, 2017. Disponível em: http://www.abepro.org.br/biblioteca/TN_WIC_238_384_34537.pdf. Acesso em: 25 jun. 2019. 
TIGRE, P. B.; MARQUES, F. S. Apropriação tecnológica na economia do conhecimento: inovação e propriedade intelectual de software na América Latina. Economia e Sociedade, Campinas, v. 18, n. 3 (37), p. 547-566, dez. 2009. Disponível em: http://www.scielo.br/pdf/ecos/v18n3/v18n3a05. Acesso em: 23 jun. 2019.

TOTVS. 5 aplicações da Inteligência Artificial na indústria que auxiliam a automatização de processos. 29 de março, 2019. Disponível em: https://www.totvs.com/blog/inteligencia-artificial-naindustria-2/. Acesso em: 29 jun. 2019.

VALOR ECONÔMICO. Tereos reduz custo e se adapta ao novo perfil de consumo de açúcar. 2019. Disponível em: https:/www.valor.com.br/agro/6181127/tereos-reduz-custo-e-se-adapta-aonovo-perfil-de-consumo-de-acucar. Acesso em: 22 jun. 2019.

VEIGA, R. Comentários sobre a nova Lei do software. Sindicato das Empresas de Processamento de Dados do Rio Grande do Sul. 1998. Disponível em: http://www.seprors.com.br/parecer.htm. Acesso em: $1^{\circ}$ jul. 1998.

VENTURELLI, M. Usina 4.0. 2015. Disponível em: http://www.usinabatatais.com.br/ noticias/2015/05/05/usina-4-0.html. Acesso em: 22 jun. 2019.

WACHOWICZ, M. Direito Autoral. 2014. Disponível em: http://www.gedai.com.br/wp-content/ uploads/2014/07/artigo_marcoswachowicz_direitoautoral_6-1.pdf. Acesso em: 19 jun. 2019.

\section{Sobre os Autores}

\section{Nilza Maria Souza Altavini}

E-mail: naltavini@gmail.com

Especialização em Direito Administrativo.

Endereço profissional: Rua Universitária, n. 1.619. Cascavel, PR. CEP: 85819-110.

\section{Daniela da Silva Gumieiro}

E-mail: danygumieiro@yahoo.com.br

MBA em Gerenciamento de Projetos.

Endereço profissional: Avenida Colombo, n. 5.790. Maringá, PR. CEP: 87020-900.

\section{Flávia Oliveira Pereira}

E-mail: oliveirap.flavia@gmail.com

Graduação em Administração.

Endereço profissional: Av. Adv. Horácio Racanello Filho, n. 5.410, Maringá, PR. CEP: 87020-035.

\section{Rejane Sartori}

E-mail:rejanestr@gmail.com

Doutorado em Engenharia e Gestão do Conhecimento. Pesquisadora do Instituto Cesumar de Ciência, Tecnologia e Inovação.

Endereço profissional: Avenida Colombo, n. 5.790. Maringá, PR. CEP: 87020-900. 